\title{
The Theory of Control of Stressed States of a Block Rock Massif with Regard to the Hierarchy of its Movements
}

\author{
Solovitskiy A.N \\ Department of Geology and Geography \\ Kemerovo State University \\ Kemerovo, Krasnaya Street, 6, \\ Kemerovo \\ Russia, 650000 \\ san.mdig@mail.ru
}

\author{
Pershin V.V. \\ T.F. Gorbachev Kuzbass State \\ University, Mining Institute \\ Russia, 650000 \\ pvv@kuszu.ru
}

\begin{abstract}
It is established that taking into account the development of geodynamic and technogenic processes in the development of the Kuzbass subsoil is an actual and multifaceted problem. Its solution is impossible without the creation of new models of deformations of blocks of the earth's crust. These processes are related to the kinematics of these processes. Flat models of the earth's crust are used to collect information about them, which do not provide adequate blocks of the earth's crust. A comprehensive approach based on the integration of Earth Sciences has been applied to implement new models of deformation of the earth's crust blocks. The theory of movements of blocks of the earth's crust of different ranks is developed, taking into account the hierarchy of the strained-deformed state of the earth's crust of Kuzbass for conducting its control. The practical use of the developed theory ensures the development of new methods of geomechanics and the expansion of information on the development of geodynamic and technogenic processes in the development of the Kuzbass subsoil.
\end{abstract}

Keywords-- block of the Earth's crust, rank, stressed state, hierarchy, kinematics, geodynamic polygon, dynamic models of deformations, geodynamic process

\section{INTRODUCTION}

Currently, at mining enterprises of Kuzbass an urgent task is to study the spatial and temporal redistribution of stresses of the earth's crust, caused by the combined effect of natural and technogenic geodynamic processes [1, 2, 3]. Control of the stressed state of a block rock massif for geomechanical support of open, underground and construction geotechnology for subsoil development is proposed to be carried out by the authors on the basis of the applied geodynamic analysis method (AGAM), which is based on the solution of fundamental and applied problems of geodynamics. The control of the stressed state of the block rock massif of the AGAM is based on a unified theory of a block rock massif that integrates the concept of "block" used in geology, mining, tectonics, and "morphostructure" in structural geomorphology. The basis of the unified theory of block rock mass is the block ierarchic structure of the earth's crust, which characterizes the severity in relief and the concentration of stress fields in fault zones, as well as the relationship of stress fields with the formation and interaction of these structures. The unified theory of a block rock massif is the result of analysis and generalization of the results of studies of related Earth sciences. The basis for its development was the scientific works of the following scientists: S. G. Artyushkova, I. M. Batugina, V. V. Belousov, K. V. Bogolepov, M. V. Gzovskogii, A. N. Dinnik, P. V. Egorova, M. A. Iofis, E.F. Kasparian, V. A. Magnitskii, Yu. A. Meshcheryakova, N. I. Nikolaeva, P. N. Nikolaeva, A. V. Orlova, I. M. Petukhov, T. Y. Piotrovskaya, M. Protodyakonov, M. A. Sadowski, D. Terkata, I. A. Turchaninov, E. M. Tsirikhova, D. L. Shevyakova, E. I. Shemyakina, A. E. Scheidegger, S. I. Sherman, John Schubert and many others $[1,4,5,6,7,8,9]$. One of the main parts of this theory is the theory of motion of blocks of the earth's crust of different ranks, which is poorly highlighted in the open press and the deformation model, taking into account the hierarchy, is not developed. Therefore, the development of the theory and methods of control of the earth's crust blocks of different ranks in the areas of coal deposits development and their dynamic deformation models is not only relevant, but it also has scientific and practical interest.

\section{THE OBJECT OF STUDY}

Kinematics of blocks of the earth's crust of different ranks, caused by changes in the time of their stress-strain state.

Main goals:

- to generalize the theoretical bases of control of the stressed state of a block rock massif;

- to develop a theory of movements of blocks of the earth's crust, taking into account the hierarchy of its structure to ensure control of the stress-strain state.

The purpose of the work is to develop control over the stress state of the earth's crust during the development of coal deposits in Kuzbass, taking into account its hierarchy to 
provide an information basis for their safety. The scientific novelty of the presented work is:

- taking into account the latest and modern movements on the basis of structural modeling of block structures;

- in the transition from flat deformation models to their values and corresponding stress values related to certain block structures;

- the integral nature of the use of modern advances in Earth sciences;

- in determining the quantitative characteristics of deformations and stresses in a block rock massif;

- in the ranking of stress and strain fields;

- in the joint definition of the dynamic parameters necessary to evaluate the interaction of block structures;

- modern technologies for conducting repeated highprecision observations on the GSA;

- the consistency and gradual transition from geometric models to physical ones;

- in the iterative approach to update the results.

Since this theory is an integral part of the information base for geomechanical support of geotechnology for the development of subsurface resources, the information obtained during its implementation must meet its basic properties:

- validity;

- reliability;

- accuracy;

- completeness;

- keeping the data up-to-date.

The theoretical significance of the research is to optimize the registration of the kinematics of the blocks of the earth's crust to determine the dynamic parameters and their interpretation, which ensures the expansion of information interaction between related Earth sciences.

The practical significance of the research is to use the results of research to solve a number of problems of geodesy, geodynamics, geomechanics and geotechnology of subsoil development that reduce the risk and reduce the consequences of manifestations of geodynamic processes in the areas of construction and operation of more than 130 coal-mining enterprises of Kuzbass.

\section{MATERIALS AND METHODS}

In our opinion, the account of the hierarchy of the earth's crust structure and the action of geodynamic processes should be reflected in this theory $[9,11,12,13,14,15]$. Geodynamic processes cause stresses in blocks of the earth's crust. The hierarchy of these stresses characterizes the change in the stress-strain state of the earth's crust blocks of different ranks, which is determined by the rank 2 tensor. Such changes cause the movement of earth's crust blocks. These movements give rise to displacement of points, the direction and magnitude of which has a complex picture, the authors propose to identify the impact of the movement of the earth's crust blocks of different ranks. Examples of changes in their deformation components in time $\left(1+10^{-6}\right)$ are obtained by the authors and shown in figures 1,2 and 3 at the same speed of their movement up to $7 \mathrm{~mm} /$ year.

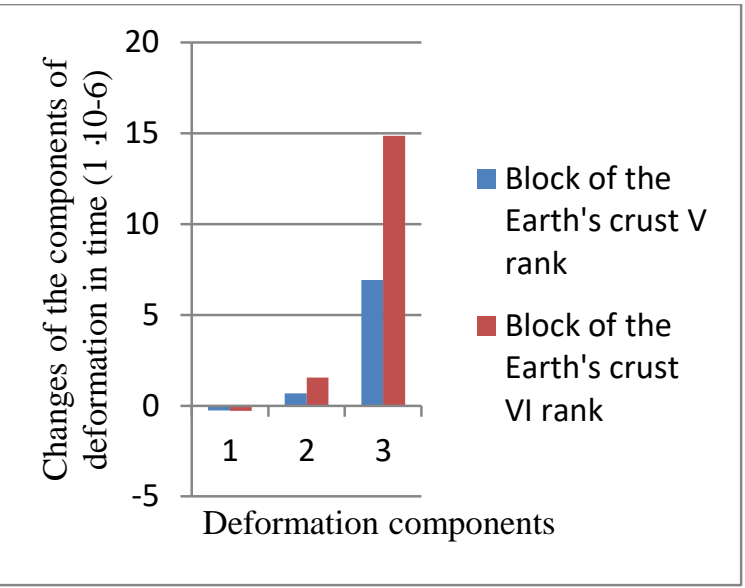

Fig.1. - Changes in the components of deformation in time of the crustal blocks of the V-VI ranks: $1-e_{11}\left[t-t_{0}\right] ; 2$ -

$$
e_{12}\left[t-t_{0}\right] ; 3-e_{13}\left[t-t_{0}\right]
$$

The investigated blocks of the earth's crust of the V-VI ranks, given in the examples (Figures 1, 2 and 3), are located south-west of the town Belovo. The movements of the blocks of the earth's crust are registered by faults according to a special technique developed by the authors $[16,17]$. Displacements of the point, the coordinates of which are $X\left[t_{0}\right], Y\left[t_{0}\right]$ and $H\left[t_{0}\right]$ for the era $t_{0}$, are treated further, as their

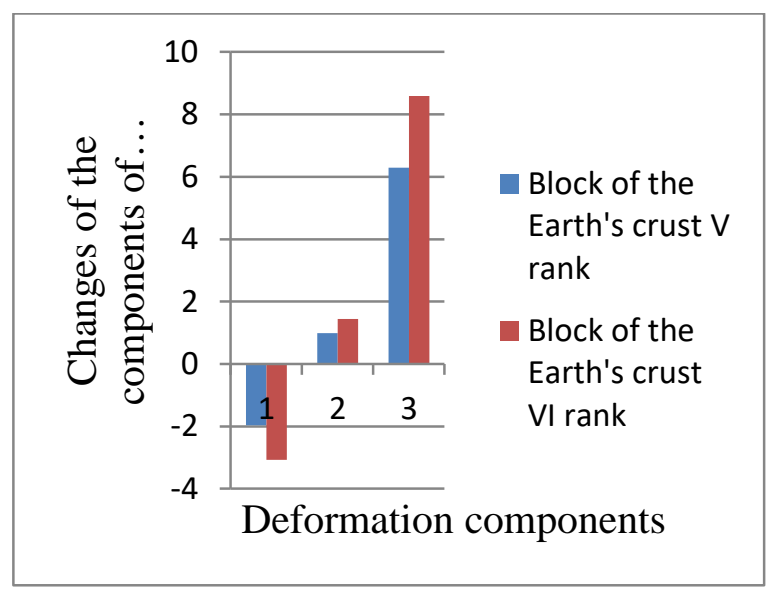

Fig. 2. - Changes in the components of deformation in time of the crust blocks V-VI ranks: $1-e_{31}\left[t-t_{0}\right] ; 2$ $e_{32}\left[t-t_{0}\right] ; 3-e_{33}\left[t-t_{0}\right]$ 


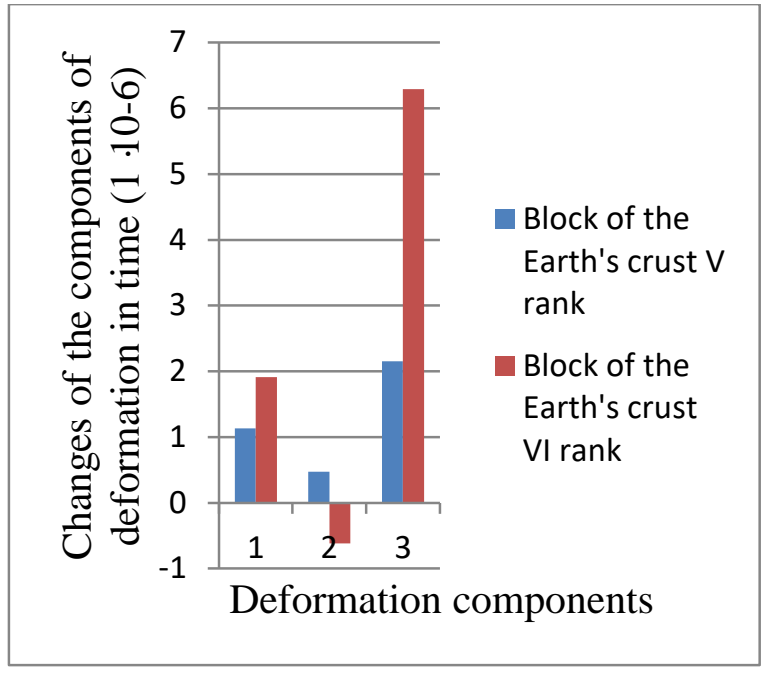

Fig. 3. - Changes in the components of deformation in time of the crust blocks of the V-VI ranks: $1-e_{21}\left[t-t_{0}\right] ; 2$ -

$e_{22}\left[t-t_{0}\right] ; 3-e_{23}\left[t-t_{0}\right]$

changes in time $\Delta X_{i}\left(r_{i}\right)\left[t-t_{0}\right], \Delta Y_{i}\left(r_{i}\right)\left[t-t_{0}\right]$ and $\Delta H_{i}\left(r_{i}\right)\left[t-t_{0}\right]$, , in the form of two terms: variable and constant. The variable components are due to the corresponding change in the stress-strain state of the earth's crust block grade $r(i)$

$\Delta X_{i}\left(r_{i}\right)\left[t-t_{0}\right]=\Delta X_{n d s}\left(r_{i}\right)\left[t-t_{0}\right]+$

$\Delta X_{0}\left(r_{i}\right)\left[t-t_{0}\right]$

$\Delta Y_{i}\left(r_{i}\right)\left[t-t_{0}\right]=\Delta Y_{n d s}\left(r_{i}\right)\left[t-t_{0}\right]+$

$\Delta Y_{0}\left(r_{i}\right)\left[t-t_{0}\right]$

$\Delta H_{i}\left(r_{i}\right)\left[t-t_{0}\right]=\Delta H_{n d s}\left(r_{i}\right)\left[t-t_{0}\right]+$

$\Delta H_{0}\left(r_{i}\right)\left[t-t_{0}\right]$

Changes in the time of coordinates $\Delta X_{i}\left(r_{i}\right)\left[t-t_{0}\right]$, $\Delta Y_{i}\left(r_{i}\right)\left[t-t_{0}\right]$ and $\Delta H_{i}\left(r_{i}\right)\left[t-t_{0}\right]$, due to the corresponding change in the stress-strain state of the block of the earth's crust rank $r(i)$, is equal to

$$
\left.\begin{array}{l}
\Delta X_{i}\left(r_{i}\right)\left[t-t_{0}\right]=X\left[t_{0}\right] e_{11}\left(r_{i}\right)\left[t-t_{0}\right]+ \\
Y\left[t_{0}\right] e_{12}\left(r_{i}\right)\left[t-t_{0}\right]+H\left[t_{0}\right] e_{13}\left(r_{i}\right)\left[t-t_{0}\right] \\
\Delta Y_{i}\left(r_{i}\right)\left[t-t_{0}\right]=X\left[t_{0}\right] e_{21}\left(r_{i}\right)\left[t-t_{0}\right]+ \\
Y\left[t_{0}\right] e_{22}\left(r_{i}\right)\left[t-t_{0}\right]+H\left[t_{0}\right] e_{23}\left(r_{i}\right)\left[t-t_{0}\right] \\
\Delta H_{i}\left(r_{i}\right)\left[t-t_{0}\right]=X\left[t_{0}\right] e_{31}\left(r_{i}\right)\left[t-t_{0}\right]+ \\
Y\left[t_{0}\right] e_{32}\left(r_{i}\right)\left[t-t_{0}\right]+H\left[t_{0}\right] e_{33}\left(r_{i}\right)\left[t-t_{0}\right]
\end{array}\right\}(2)
$$

where $e_{13} r(i)\left[t-t_{0}\right], e_{12} r(i)\left[t-t_{0}\right], e_{13} r(i)\left[t-t_{0}\right]$, $e_{21} r(i)\left[t-t_{0}\right], \quad e_{22} r(i)\left[t-t_{0}\right], \quad e_{23} r(i)\left[t-t_{0}\right]$, $e_{31} r(i)\left[t-t_{0}\right], e_{32} r(i)\left[t-t_{0}\right]$ and $e_{33} r(i)\left[t-t_{0}\right]-$ changes in the components of the deformation in time of the crust block of rank $r(i)$ during the period $\left[t-t_{0}\right]$.

The authors assessed the influence of changes in the stress-strain state of the earth's crust blocks of III-VI ranks on the change in time of the coordinates of the point according to the program "BM" developed by them [16] on the example of the data given above and illustrated in figures 4 and 5.

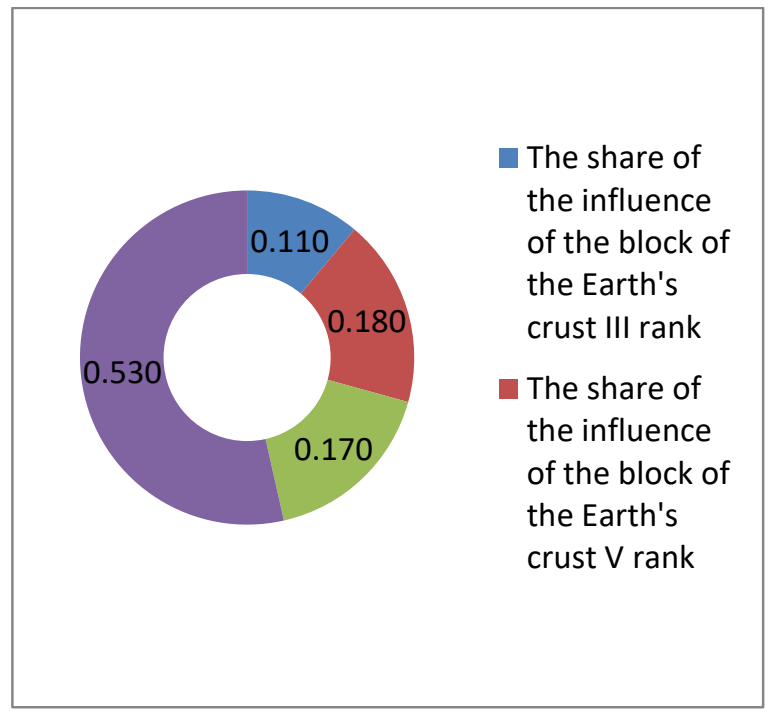

Fig. 4. The share of the influence of changes in the stressstrain state of blocks of the earth's crust of different ranks on the change in the time of the abscissa of point

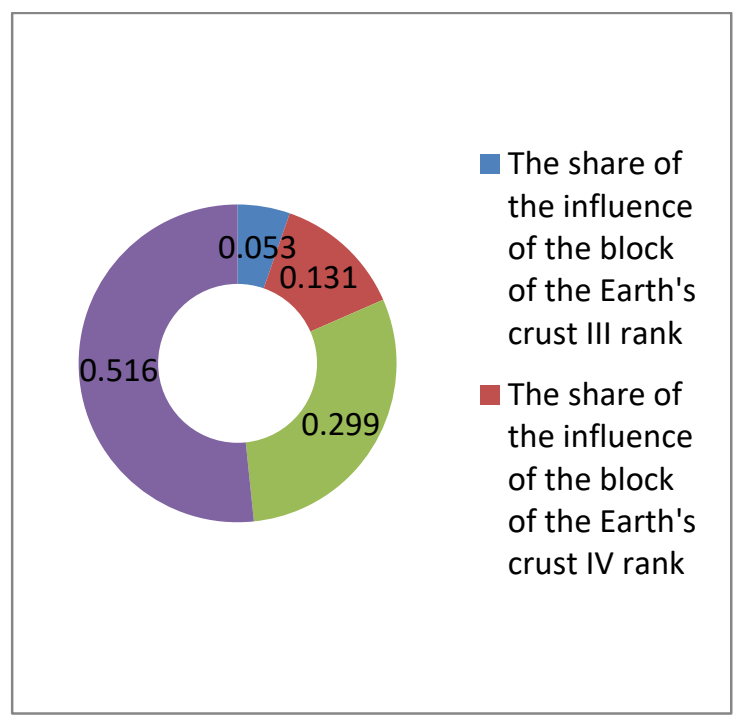

Fig. 5. The share of the effect of changes in the stress-strain state of the blocks of the earth's crust of different ranks on the change in time the variation of the height of the point

\section{RESULTS AND DISCUSSION}

To implement the control of the stressed state of blocks of the earth's crust of different ranks, the authors propose 
multi-level geodesic constructions and the of a complex geodynamic polygon (Fig. 6). At the points of such constructions, the authors developed a technology for recording the kinematics of blocks of the earth's crust. These items (Fig. 6) are divided into mobile and stable. Mobile points are fixed in each block of the earth's crust, and stable ones are in a conditionally stable block.

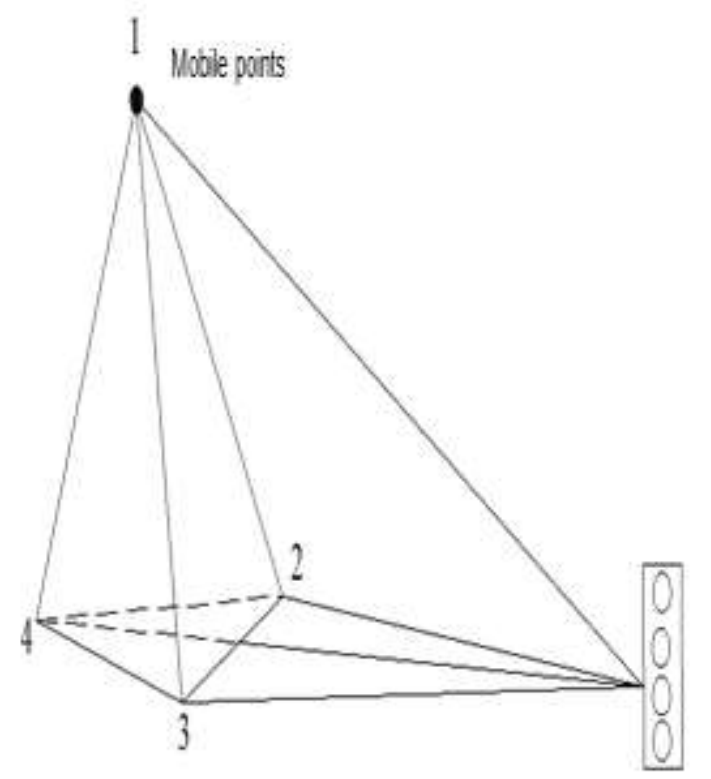

Stable poirts

Fig. 6. Scheme of the elementary cell of geodetic constructions on the FDP

when carrying out geodynamic studies at geodynamic polygons, the time variations in the increments of the points are usually determined to be relatively stable. In this case, equations (1) and (2) have the form:

$$
\begin{aligned}
& \partial \Delta X_{c i}\left(r_{i}\right)\left[t-t_{0}\right]=X\left[t_{0}\right] e_{11}\left(r_{i}\right)\left[t-t_{0}\right]- \\
& X_{c}\left[t_{0}\right] e_{11}^{0}\left(r_{i}\right)\left[t_{0}\right] \\
& +Y\left[t_{0}\right] e_{12}\left(r_{i}\right)\left[t-t_{0}\right]-Y_{c}\left[t_{0}\right] e_{12}^{0}\left(r_{i}\right)\left[t_{0}\right] \\
& +H\left[t_{0}\right] e_{13}\left(r_{i}\right)\left[t-t_{0}\right]-H_{c}\left[t_{0}\right] e_{13}^{0}\left(r_{i}\right)\left[t_{0}\right] \\
& \partial \Delta Y_{c i}\left(r_{\sum}\right)\left[t-t_{0}\right]=X\left[t_{0}\right] \sum e_{21}\left(r_{i}\right)\left[t-t_{0}\right]- \\
& X_{c}\left[t_{0}\right] e_{21}^{0}\left(r_{i}\right)\left[t_{0}\right] \\
& +Y\left[t_{0}\right] \sum e_{22}\left(r_{i}\right)\left[t-t_{0}\right]-Y_{c}\left[t_{0}\right] e_{22}^{0}\left(r_{i}\right)\left[t_{0}\right] \\
& +H\left[t_{0}\right] \sum e_{23}\left(r_{i}\right)\left[t-t_{0}\right]-H_{c}\left[t_{0}\right] e_{23}^{0}\left(r_{i}\right)\left[t_{0}\right]
\end{aligned}
$$

$$
\begin{aligned}
& \partial \Delta H_{c i}\left(r_{i}\right)\left[t-t_{0}\right]=X\left[t_{0}\right] e_{31}\left(r_{i}\right)\left[t-t_{0}\right]- \\
& X_{c}\left[t_{0}\right] e_{31}^{0}\left(r_{i}\right)\left[t_{0}\right] \\
& +Y\left[t_{0}\right] e_{32}\left(r_{i}\right)\left[t-t_{0}\right]-Y_{c}\left[t_{0}\right] e_{32}^{0}\left(r_{i}\right)\left[t_{0}\right] \\
& +H\left[t_{0}\right] e_{33}\left(r_{i}\right)\left[t-t_{0}\right]-H_{c}\left[t_{0}\right] e_{33}^{0}\left(r_{i}\right)\left[t_{0}\right]
\end{aligned}
$$

where $e_{11} r^{0}(i)\left[t-t_{0}\right], e_{12} r^{0}(i)\left[t-t_{0}\right], e_{13} r^{0}(i)\left[t-t_{0}\right]$, $e_{21} r^{0}(i)\left[t-t_{0}\right], e_{22} r^{0}(i)\left[t-t_{0}\right], e_{23} r^{0}(i)\left[t-t_{0}\right]$, $e_{31} r^{0}(i)\left[t-t_{0}\right], e_{32} r^{0}(i)\left[t-t_{0}\right]$ and $e_{33} r^{0}(i)\left[t-t_{0}\right]-$ changes of deformation components in time of a stable block of the earth's crust of rank $r(i)$ during the period $\left[t-t_{0}\right]$; $X_{c}\left[t_{0}\right], \quad Y_{c}\left[t_{0}\right], H_{c}\left[t_{0}\right]$ - coordinates of the stable reference point for the era $t_{0}$.

The authors offer a generalized idea of the measured increments of coordinates $\partial \Delta X_{c i}$ (changes) $\left[t-t_{0}\right]$ and $\partial \Delta Y_{c i}$ (changes) $\left[t-t_{0}\right]$ during geodynamic studies in the Kuzbass in the following form:

$$
\begin{aligned}
& \partial \Delta X_{c i}(\text { changes })\left[t-t_{0}\right]=\partial \Delta X_{c i}\left(r_{i}\right)\left[t-t_{0}\right)+ \\
& \partial \Delta X_{c i}(c g f)\left[t-t_{0}\right] \\
& +\partial \Delta X_{c i}(e x)\left[t-t_{0}\right] \\
& \partial \Delta Y_{c i}(\text { changes })\left[t-t_{0}\right]=\partial \Delta Y_{c i}\left(r_{i}\right)\left[t-t_{0}\right)+ \\
& \partial \Delta Y_{c i}(c g f)\left[t-t_{0}\right] \\
& +\partial \Delta Y_{c i}(\text { ex })\left[t-t_{0}\right] \\
& \partial \Delta H_{c i}(\text { changes })\left[t-t_{0}\right]=\partial \Delta H_{c i}\left(r_{i}\right)\left[t-t_{0}\right)+ \\
& \partial \Delta H_{c i}(c g f)\left[t-t_{0}\right] \\
& +\partial \Delta H_{c i}(\text { ex })\left[t-t_{0}\right]
\end{aligned}
$$

Where $\partial \Delta X_{c i}(c g f)\left[t-t_{0}\right], \quad \partial \Delta Y_{c i}(c g f)\left[t-t_{0}\right] \quad$ and $\partial \Delta H_{c i}(c g f)\left[t-t_{0}\right]$ - changes in exceedances and increments of coordinates in time, due to the influence of changes in the gravitational field; $\partial \Delta X_{c i}(e x)\left[t-t_{0}\right]$, $\partial \Delta Y_{c i}(e x)\left[t-t_{0}\right]$ and $\partial \Delta H_{c i}(e x)\left[t-t_{0}\right]$ - changes in exceedances and increments of coordinates in time, due to the influence of exogenous processes.

The technology for determining the changes in increments of coordinates and time excesses due to the influence of changes in the gravitational field during the development of subsoil in the Kuznetsk Basin has been developed and outlined in $[16,17]$. The study of changes in coordinate increments in time, caused by the influence of exogenous processes, is a problem requiring separate consideration. 


\section{CONCLUSION}

On the basis of the carried-out researches the following conclusions are made:

1. It is established that the study of the development and spatial-temporal redistribution of earth's crust stresses caused by the joint influence of natural and technogenic geodynamic processes in the mining enterprises of Kuzbass is an actual and multidimensional problem.

2. The reliability of geodynamic studies at Kuzbass mining enterprises is determined both by the choice of a stable point and by taking into account the regularities of displacement of points belonging to the earth's crust blocks of different ranks.

3. The theory of motions is developed during geodynamic studies taking into account the hierarchy of the strained-deformed state of the earth's crust of Kuzbass for carrying out its control, which not only increases the use of geodetic information about them in geomechanics, but also its use in the creation of new research methods, as geodynamic polygons, which are radically different from traditional technologies by recording and interpreting repeated observations.

\section{REFERENCES}

[1] A. A. Kozyrev, I. E. Semenova, V.V. Rybin, I. M. Avetisyan. Stress redistribution in deep open pit mine zhelesny at kovdor iron deposit. Journal of Mining Science, 51, 4 (2015).

[2] B. G. Saksin, I. Y. Rasskazov, B. F. Shevchenko Principles of integrated analysis of modern stresses and statins in the outer otust of the Amurian plate. Journal of Mining Science, 51, 2 (2015).

[3] G. G. Kocharyan, A.A. Ostapchuk. Acoustic emission during differenttype inter-block movements. Journal of Mining Science, 51, 1(2015).

[4] A. A. Mylnikova, Yu. V. Yasyukevich, E. V. Kunitsyu. Varialility of GPS/GLONASS differential code baises. Results in Physics. 5, (2015).
[5] A. P. Karpik, I. G. Ganagina, S. N. Kosarev, D. N.Goldobin. Navigation and information system of precise transport positioning using the ground infrastructure GLONASS // Gyroscopy and Navigation, 7, 1(2016).

[6] E. G. Kassikhina, V. V. Pershin, J. F. Glazkov. New Technical Solution for Vertical Shaft Equipping Using Steel Headframe of Multifunction Purpose. E3S Web of Conferences, IInd International Innovative Mining Symposium, 1 (Devoted to Russian Federation Year of Environment 2017) https://doi.org/10.1051/e3sconf/20172101007

[7] M. G. Kogan, G. M. Steblov Current global plate kinematics from GPS (1995-2007) with the plate-consistent reference frame // Journal Geophys Res., 113, B04416(2008)

[8] C. DeMets, R. G. Gordon, D. F. Argus Geologically current plate motions. Geophys Journal Int., 181, (2010).

[9] D. F. Argus, R. G. Gordon, M. B. Heflin, C. Ma, R. J Eanes, P. Willis, W. R. Peltier, S. Owen. The angular velocities of the plates and the velocity of Earth's centre from space geodesy. Geoophys Journal Int., 180, (2010).

[10] R. McCaffrey. Block kinematics of the Pacific-North America plate boundary in the southwestern United States from inversion of GPS, seismological, and geologic data. Journal Geophys. Res.,110, B07401(2005).

[11] J. C. Savage, W. Gan, J. L. Svarc. Strain accumulation and rotation in the eastern California shear zone // Journal Geophys. Res., 106, (2001).

[12] Rojas-Sola J. I., Montalvo-Gil J. M., Castro-Garcia M. 3D modeling and functional analysis of a headframe for mineral extraction. Dyna, Vol. 80, No. 181 , https://www.expeducation.ru/ru/article/view?id=7319

[13] T. Terada, N. Miyabe. Deformation of the earth crust in Kwansai districts and its relation to the orographic feature. Bull. Earthquake Res. Inst. 7, (1929).

[14] Z. Shen, D. D. Jackson, B. X. Ge. Crustal deformation across and beyond the Los Angels Basin from geodetic measurements. Journal Geophys. Res., 101, (1996).

[15] P. Bird. An updated digital model of plate boundaries. Geochem. Geophys. Geosystems. 4, 3(2003).

[16] A. Solovitskiy. Dynamic models of deformation of crustal blocks in the area of development of coal deposits - the basis of the information security of their development // 8th Russian-Chinese Symposium. Coal in the 21st Century: Mining, Processing and Safety. - September, (2016). http://www.atlantis-press.com/php/pub.php?publication=coal-16

[17] V. Perhin , A. Solovitskiy . Nev Opportunities to Expand Information on Intens - Strained State of the Eart's Crust in the Areas of Development Mineral Resources During Monitoring Greation // The Second International Innovative Mining Symposium. - November, (2017). http://doi.org/10.1051/e3sconf/

20172101009 